This item was submitted to Loughborough's Research Repository by the author.

Items in Figshare are protected by copyright, with all rights reserved, unless otherwise indicated.

\title{
Additive manufacturing in South Africa: building on the foundations
}

PLEASE CITE THE PUBLISHED VERSION

http://dx.doi.org/10.1108/13552541111113907

PUBLISHER

(C) Emerald

VERSION

AM (Accepted Manuscript)

LICENCE

CC BY-NC-ND 4.0

REPOSITORY RECORD

Campbell, R.I., D.J. de Beer, and Eujin Pei. 2019. "Additive Manufacturing in South Africa: Building on the Foundations". figshare. https://hdl.handle.net/2134/9759. 
This item was submitted to Loughborough's Institutional Repository (https://dspace.lboro.ac.uk/) by the author and is made available under the following Creative Commons Licence conditions.

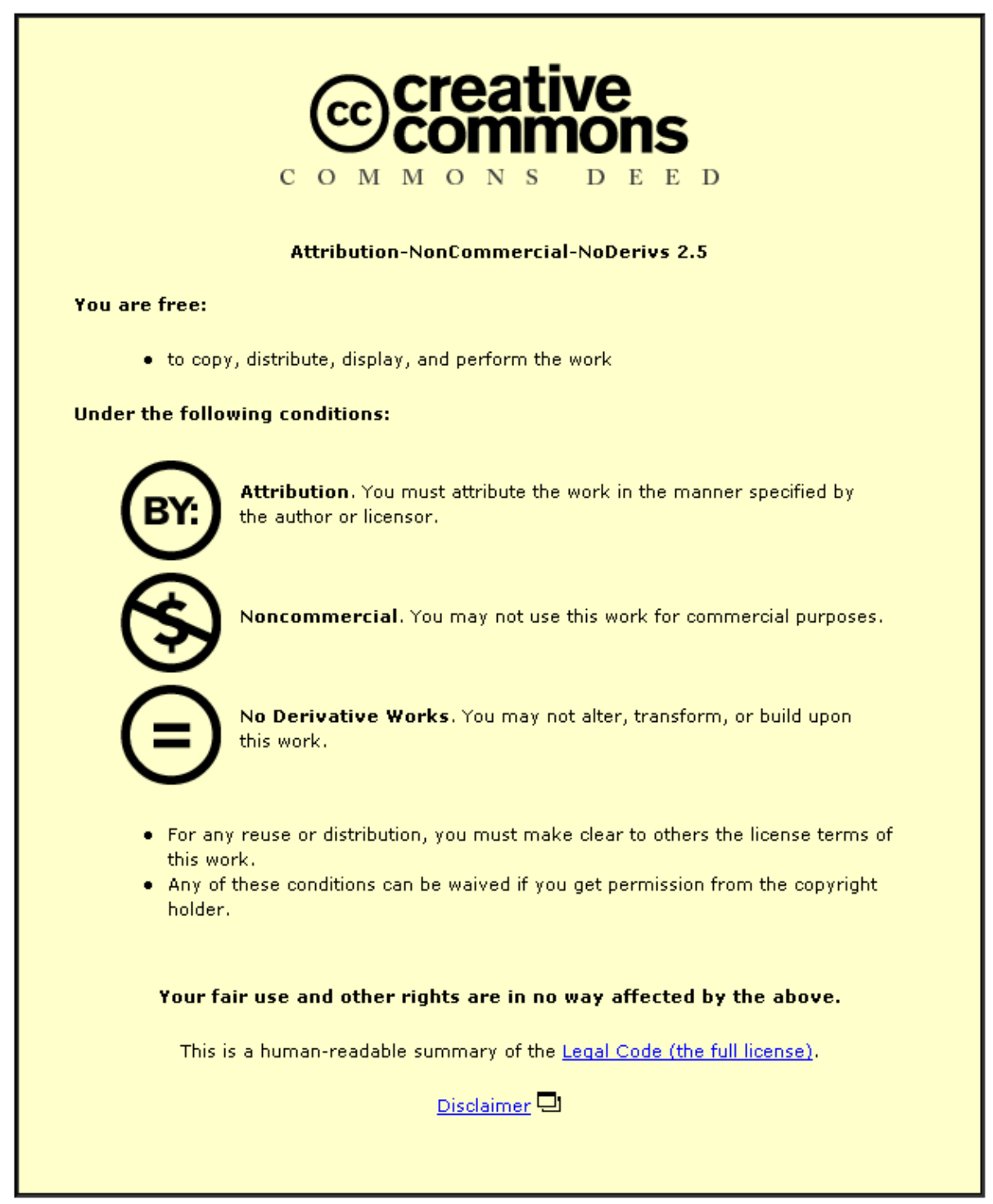

For the full text of this licence, please go to: http://creativecommons.org/licenses/by-nc-nd/2.5/ 


\title{
Additive Manufacturing in South Africa: building on the foundations
}

\author{
R I Campbell*, D J de Beer** and E Pei***
}

* Dr Ian Campbell is leader of the Design Practice Research Group at Loughborough University, UK and a Visiting Scientist at the Vaal University of Technology, South Africa

r.i.campbell@lboro.ac.uk

Tel +441509228312, Fax +441509 223999

** Prof Deon de Beer is Executive Director: Technology Transfer \& Innovation at the Vaal University of Technology, South Africa.

deond@vut.ac.za

Tel: +27 (0)16950 9153, Fax: +27 (0)169509270

*** Dr Eujin Pei is currently working as a Visiting Scientist at the Vaal University of Technology, South Africa.

e.pei@lboro.ac.uk

Tel +44 1509228312, Fax +44 1509223999 


\section{Additive Manufacturing in South Africa: Building on the Foundations}

\section{Type of Paper}

General Review

\section{Purpose}

In a previous Rapid Prototyping Journal paper, the authors reviewed the first decade of Rapid Prototyping (RP) use within the Republic of South Africa (RSA). The paper analysed its strengths, weaknesses, opportunities and threats, and proposed a "road-map" for future development. Much has happened in the intervening years since that article was published and this paper seeks to update readers on the current situation in RSA. In particular, it reports the extensive development of research in the field of RP and Additive Manufacturing (AM).

\section{Methodology}

The paper uses a literature review approach combined with reflective analysis to distill the most important developments within the RP community in RSA since 2004. These are compared to the previous road-map to ascertain if there are any required actions that have been overlooked or any additional lessons that have been learnt.

\section{Findings}

The paper shows that there has been good progress against the previous road-map and that current plans should remain in place with the addition of a greater educational dimension.

\section{Practical Implications}

This paper provides readers with an overview of important RP/AM developments in the RSA. The analysis from this the paper will aid RSA academics, industrialists and government agencies to assess their performance and to plan for their future roles within the RP community.

\section{Value}

As with the previous paper, this article provides a useful model for other countries to follow since it demonstrates both good practice but also the need to learn from past experience.

\section{Keywords}

Rapid Prototyping, Additive Manufacturing, South Africa 


\section{Introduction}

As with all nations, the Republic of South Africa (RSA) has a unique set of circumstances and challenges. Emerging from economic isolation and stagnation, the RSA has some highly developed regions but also some pockets of poorly developed infrastructure. Therefore, developing countries can learn from the way it has sought to modernise its industries and to look for guidance. In relation to technology, the RSA has embraced rapid prototyping (RP) as a method of revolutionising its industry. According to du Preez et al., (2006), the first RP systems were installed in the RSA in 1994. Since then, its uptake has advanced rapidly. Many other countries are following this path of late adoption and so can learn valuable lessons from what has happened in the RSA.

This paper seeks to review recent RP and additive manufacturing (AM) developments within the RSA and analyses its success in using the opportunities that were previously discussed. A thorough review of RP/AM research and other activities are presented. The paper goes on to identify future lessons that can be learnt and proposes an updated road-map to aid the future direction of RP/AM application in the country.

\section{Overview of the Situation in 2004}

Towards the end of 2004, the RP community in RSA was in a very healthy state. RP machine installations were rising quickly and research was moving into new fields with government initiatives being successful in bringing industry and academia together. A number of trends had started to emerge, particularly the move towards $3 D$ printers and other RP installations within industry. The Rapid Product Development Association of South Africa (RAPDASA) played a crucial role in raising RP awareness through organising an annual conference and forged international links with GARPA (the Global Alliance of Rapid Prototyping Associations). However, a number of weaknesses and potential threats were also identified (Campbell and de Beer, 2005). The range of RP/AM systems and material combinations within the country were severely limited and fabrication times could be long. Some major RSA industries were still not embracing RP/AM, possibly because they were relying on designs from companies outside of the country. It was also found that there was a lack of fundamental research in higher institutions that made peer-reviewed publications hard to achieve. Finally, there was growing competition in the tooling industry from overseas, especially China. To build on strengths and to combat weaknesses, a road-map for the future of RP was proposed by the authors. From the paper, 
"Rapid Prototyping in South Africa: Past, Present and Future" (Campbell and de Beer, 2005) the main recommendations were:

1. To increase participation of industry within national RP networks, supported and encouraged by RAPDASA.

2. To embrace product development activities which use digital tools that facilitate and compliment RP, e.g. solid modelling.

3. To strengthen key international links, including more RP vendors being encouraged to establish a presence within RSA.

4. To develop the RSA as a conduit to neighbouring countries and other parts of Africa.

This road-map that was generated will act as a benchmark to evaluate subsequent developments that are discussed in this paper.

\section{RP Developments since 2004}

The use of RP and related technologies, such as computer aided design (CAD) and rapid tooling (RT), has grown rapidly in the RSA. Between 2005 and 2006, the total number of RP machines installed doubled (Wohlers, 2006, 2007). Growth slowed down between 2007 and 2008 to around $24 \%$ and $21 \%$ respectively (Wohlers, 2008, 2009). In recent years, RP and RT technologies have been joined by AM as designers began to embrace the advantages that could bring geometric freedom in small batch production. A key enabler for the uptake of AM has been the broadening of the technologies available, such as Direct Metal Laser Sintering (DMLS) which was introduced to the Central University of Technology (CUT), Free State in 2006. Practitioners and researchers have been pushing boundaries every year, with new developments and case studies being reported. Although all of the major universities have a strong presence in manufacturing research, AM-related research is being driven by a minority (39\%), whilst some more have AM facilities used to support other manufacturing research, giving a total of $48 \%$ of universities having AM facilities in-house. 


\subsection{RP System Installations and Ownership Trends}

De Beer (2008) reported that the rapid growth in RP machine installations beginning in 2004 had continued in subsequent years as shown in Figure 1. He also found that the dominance of $3 \mathrm{D}$ printers had increased, accounting for $92 \%$ of the RP systems sold in 2007. As a result, approximately $88 \%$ of the estimated $136 \mathrm{RP}$ machines running in the RSA at the end of 2008 were $3 \mathrm{D}$ printers. The predominant reason for this would appear to be cost, but improved part quality and easier materials handling have also played a role (Wohlers, 2008).

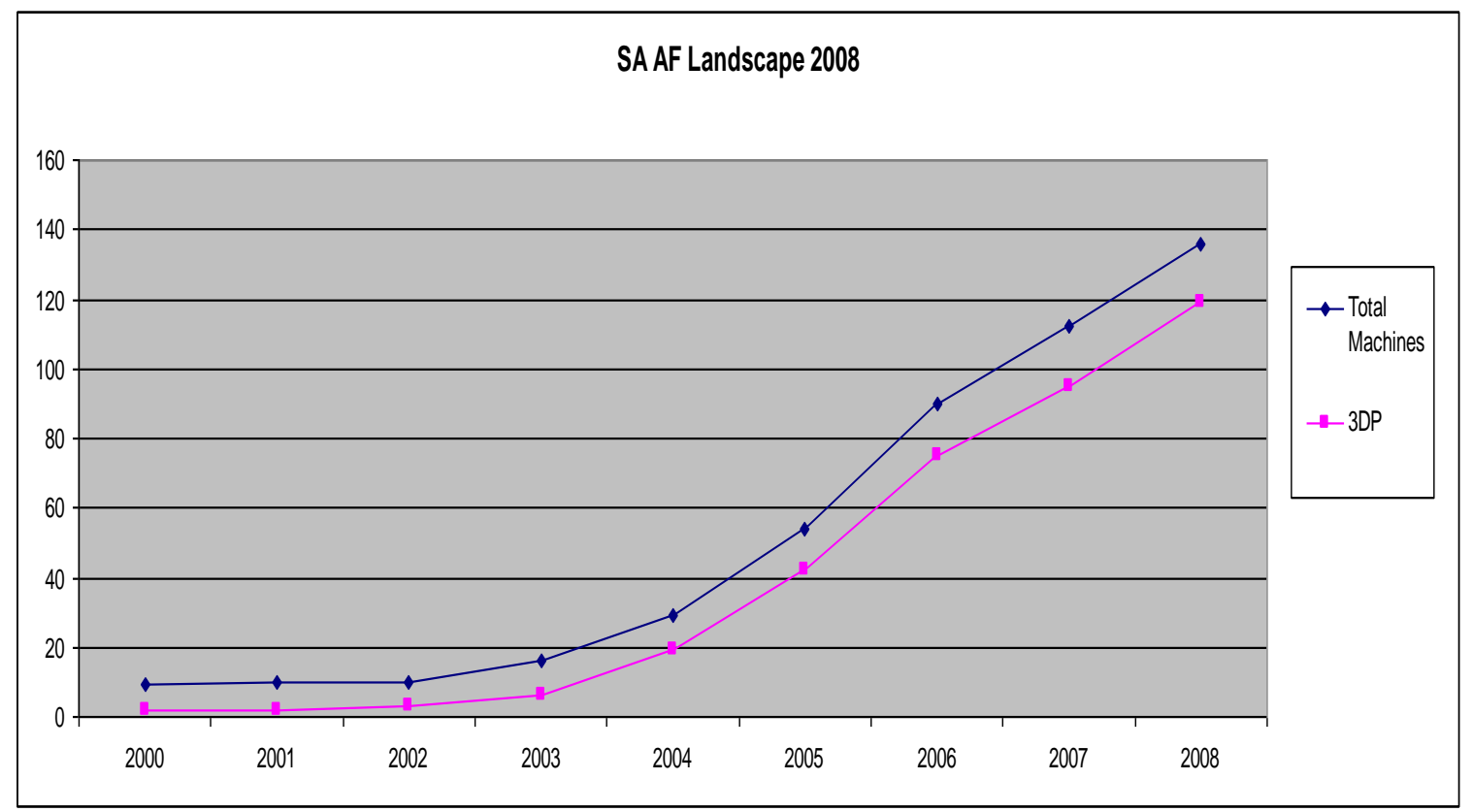

Figure 1: Growth of RP machine base in RSA, 2000 to 2008 (De Beer, 2008)

An interesting trend is that industrial ownership has outgrown academic ownership of RP systems (Wohlers, 2009). In the early years beginning from 1998, only one RP system was owned by a private company (du Preez et al., 2006). RP was initially introduced into higher education and research centres but towards the end of 2005, out of the 54 RP machines in the RSA, 40 of these $(74 \%)$ belonged to private companies. These findings are in line with those of Dimitrov, D. et al. (2008). The rise of 3D printers has seen a wide variety of industries becoming involved in additive manufacture, probably as a result of South Africa's National R\&D Strategy which has attempted to draw SMMEs (small, micro and medium-sized enterprises) into the country's Innovation Network. This trend illustrates that technology transfer programmes from universities to industry with government support have paid off. 
For the number of machines available in SA as reported (Wohlers, 2009), it is estimated that the replacement value (calculated on the same year's machine costs) for the total number of machines, was approximately US $\$ 9.25$ million. Replacement costs of high end machines would constitute approximately $54 \%$ of this cost, whilst the replacement costs of 3D printers would constitute the remaining $46 \%$. In looking at the distribution of high-end machines, seven organizations are represented, of which four are universities or research institutes, and three are private companies. The three companies mentioned only own 3 of the 16 reported high end machines. In terms of the 3D printers, it is estimated that approximately $90 \%$ of the total number of machines are owned and used are in industry (Figure 2 shows the statistics of SA machine ownership and industry/university comparisons).

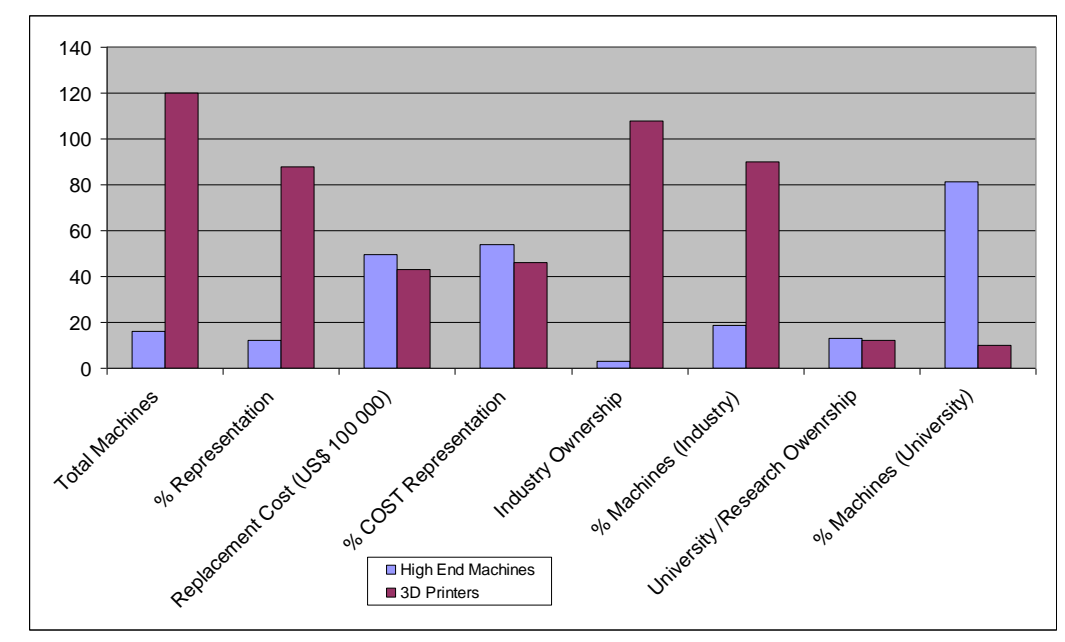

Figure 2: Comparative ownership statistics between industry and academia

In addition to their lower purchase cost, the fact that annual maintenance costs for 3D printers may be as little as $20 \%-50 \%$ of that for a high end machine explains why 3D printers have become a popular choice for small companies wanting to have in-house RP capabilities. It is likely that purchasing decisions in small, medium and micro enterprises (SMMEs) are being driven largely by cost. The authors are of the opinion that "part quality" enjoys less consideration in an SMME's decision to purchase a specific machine. For 3D printers, the element of part production cost that can be attributed to machine price and maintenance cost (divided by an assumed hourly annum usage), is more likely to fit an SMME's available budget. The further element of that depends on consumable costs may not greatly influence the purchase decision, but the ordering of material start-up quantities and its associated costs may have a direct 
influence. Although it may be reasoned that part cost on high end machines can, in some cases, be less than on 3D printers, this also is a function of machine utilisation rates. Once again an SMME may accept that they have to pay more per part but that these costs can be spread over a longer period of time (associated with a low utilisation rate). In return they can invest less on hardware initially and are not forced to import consumable material in bulk (as is the case with most of the high end machines in the RSA). The availability of local agents and "off the shelf" consumable material is obviously an important factor here, which within the current situation, is more viable for certain 3D printing OEMs, through having agents in the RSA.

The applications for 3D printers, with the exception of a few research institutes and industry users, are mainly for the fast production of concept models, often used for design verification, form fit and function tests or geometrical / functional representation. In contrast, all high end machines are additionally involved in advanced applications such as tooling, masters for investment casting or direct digital manufacturing of end products.

\subsection{RP Research and Applications}

Whereas more universities in the RSA are becoming involved in RP/AM research, the University of Stellenbosch and the CUT are still the current leaders. Research has been focused towards new materials and improving machine accuracy. Research teams have also investigated novel industrial applications where little or no previous research had been done. Examples include the use of RP models for visualisation in architecture (Figure 3) (de Beer et al, 2004) and the use of ground information systems (GIS) data to construct physical models of rain catchment areas (Figure 4) (Agrawal et al, 2006). Other applications include injection mould trials using the EOS Alumide material (de Beer et al, 2005a), and the development of novel RT process chains for large sand casting components (Dimitrov et al, 2007a, 2007b).

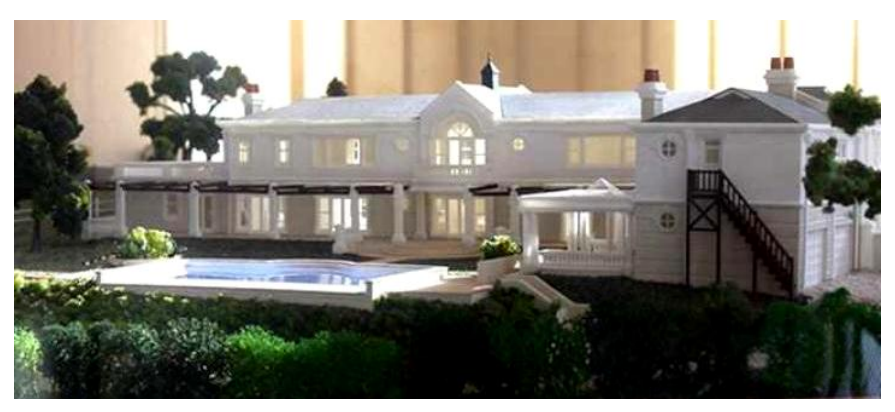

Figure 3: Architectural model created using laser sintering (de Beer et al, 2004) 


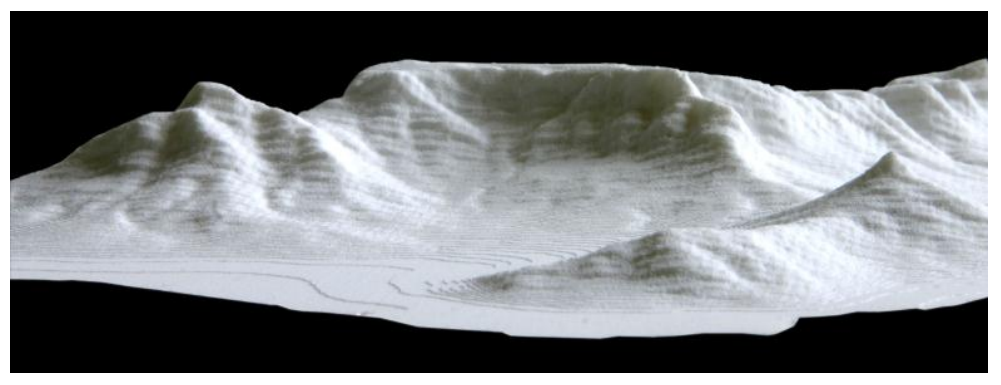

Figure 4: Laser sintered model of rain catchment area created from GIS data (Agrawal et al, 2006)

Medical applications involving the use of RP techniques have advanced within the RSA through a combination of $\mathrm{CT}$ and MRI scanning, reverse engineering, RP/AM and computer numerical control (CNC) machining. Collaborative development work between the CUT and a team of surgeons and biomedical engineers have resulted in several innovative projects. They include patient-specific X-ray shielding masks (de Beer et al, 2005b), customised manufacture of medical prosthetics (Truscott et al, 2007), elbow implants fabricated using CNC (Figure 5) and cranial implants produced directly out of Titanium alloys using Selective Laser Melting at CUT, as reported by Drstvensek, et al. (2009).

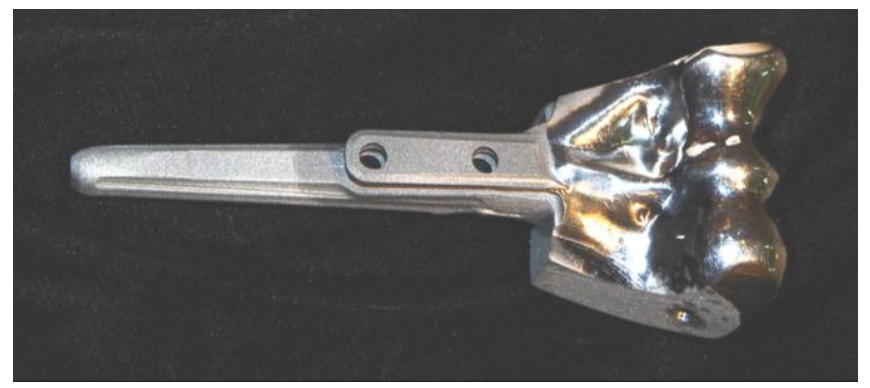

Figure 5: Titanium elbow implant manufactured after RP design verification (Truscott et al, 2007)

For medical applications, RP technologies were used because of the relatively low mechanical stresses presented and also because of the high aesthetic demands that were required. Current research is now focused towards Direct Laser Sintering of Titanium that would yield benefits in terms of material utilisation, optimised geometry and reduced lead-time. Another area of research developed from a collaborative partnership between CUT and Loughborough University in the United Kingdom concerned the application of customer interaction with 
functional prototypes (CIFP). It saw the development of a new range of motion analysis accessories produced directly from Laser Sintering (Figure 6).
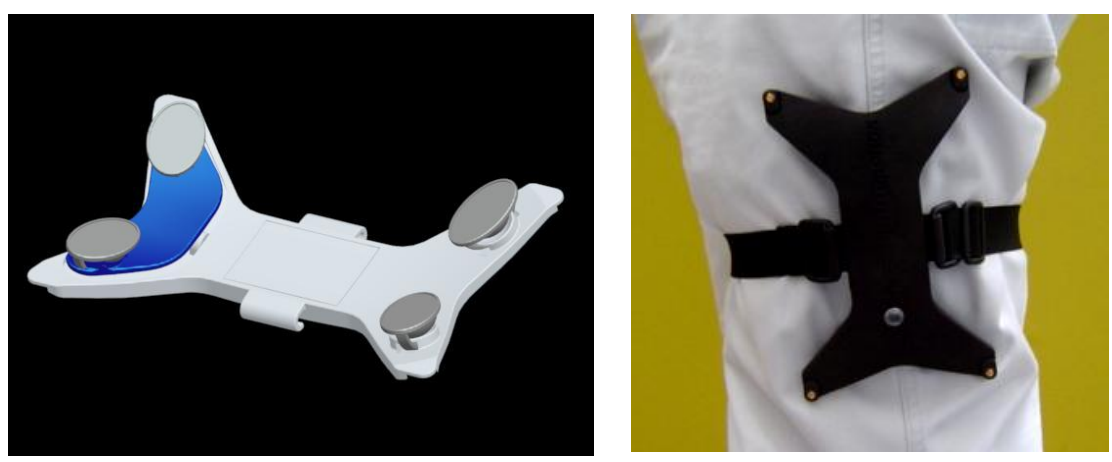

Figure 6: Motion capture system accessory (Campbell et al, 2007)

The use of RP technologies have increased the fidelity of physical models in terms of aesthetics, ergonomics and functionality. The results have facilitated greater customer participation during product development and allowed ideas to be tested to reduce the risk of failure in the market (Campbell et al, 2007)

\subsection{Industrial Utilisation of Rapid Technologies}

In the automotive and aerospace industries within the rapid technologies domain, master patterns and moulds for casting are as important as dies used for injection moulding. The increasing choice of materials available has positively influenced industry's acceptance of AM, with excellent results achieved such as the fabrication of an Alumide turbine which successfully ran at 12000 revs/min (Figure 7). According to Professor Dimitri Dimitrov, Head of the University of Stellenbosch's Laboratory for Rapid Product Development (LRPD), the use of technologies such as 3D printing is cost-effective, versatile, fast and easy to operate (Dimitrov, 2006). In addition, its accuracy, strength, surface finish, build speed and cost, allow a good price to performance ratio. The findings are in-line with Haskins (2008) who also reported that digital technologies integrated with $3 \mathrm{D}$ printing enable a fast, affordable way to produce physical prototypes directly from CAD data. It is fair to say that the major South African industry sectors all use RP technologies in some or other way. These include government and military, aerospace, automotive, medical, academic and research, sport, gaming and ICT, toys, art and craft, consumer goods as well as other ad-hoc projects. Prototypes are being used for design verification and approval, visual aids for engineering and toolmakers, functional models, fit and assembly purposes, testing, patterns for metal cast metal processes, tooling components, direct 
manufacturing and marketing. Consequently, the availability of rapid technologies in the RSA has given rise to a knock-on effect on the use of CAD, with vendors reporting increased sales of $3 \mathrm{D}$ design programs. In terms of software support for RP, specialised software such as Materialise's Magics RP, Trimatic and Mimics are now gaining popularity (Wohlers, 2009). RSA industries continue to play a key role in RAPDASA as demonstrated by the continuing success of the association's yearly organised conference. Recent seminars have also seen increased participation by RP vendors and these events function as a platform for national and international collaboration.

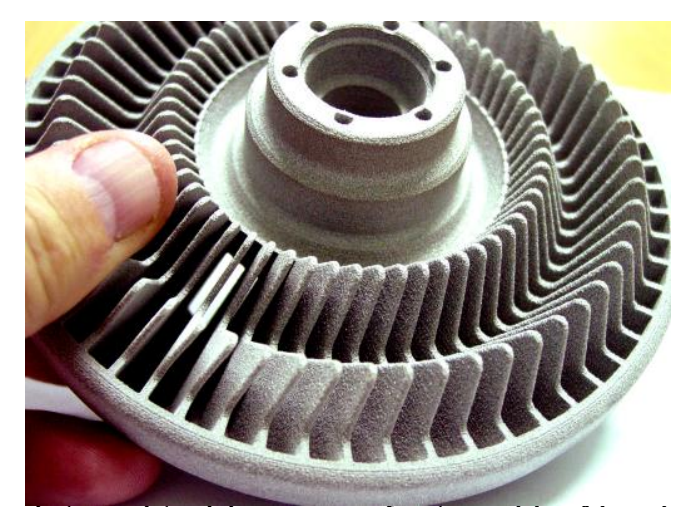

Figure 7: Laser sintered turbıne manutactured in Alumıde material.

\subsection{Government Initiatives}

To help promote the use of RP/AM in manufacturing industry and academic institutions, the RSA National Government has launched several initiatives. Perhaps the most interesting of these is the "Fab Lab" initiative. It is part of the Government's Advanced Manufacturing Technology Strategy (AMTS), and is based on MIT's successful initiative (Fab Lab, 2009). Fab Labs provide widespread access to modern means for invention and contain programmable equipment that can be used to support a wide range of projects. In collaboration with MIT, six Fab Labs have been started across the country, implying that the RSA is now taking a lead to educate and expose learners and practitioners to layered manufacturing and other CAD fabrication techniques. Fab Lab records show that young people are amongst the top and most frequent users. Other AMTS initiatives have included the Light Materials Flagship Programme, the Advanced Production Technologies Flagship Programme and Advanced Manufacturing Technology Laboratories (AMTS, 2009). Many of these programmes have aspects which are directly related to RP/AM. In particular, the Advanced Production Technologies Flagship Program offered a sub-structure specialising in Digital and Micro Manufacturing (AMTS, 2008). Although it could be argued that mainstream RP/AM has not yet reached a micro-level 
resolution, it is still possible to manufacture sub-millimetre features with some systems. In addition, three Institutes of Advanced Tooling (IAT's) have been added to the existing Tshumisano Technology Transfer Programme (Tshumisano, 2009) administered by the Department of Science and Technology (DST). The Tshumisano partnerships focus on technology transfers between South African Universities of Technology with SMMEs.

\subsection{The Role of RAPDASA}

RAPDASA has maintained its important role within the RP community of South Africa. The annual conferences that have been running since 2000 continue to attract sizable audiences from both academia and businesses. The RP industry is very well represented on the RAPDASA management committee with approximately $40 \%$ of its members coming from RP users and suppliers. These activities are aimed towards industry support and encourage the greater use of all digital technologies during new product development. As well as promoting RP within the RSA, these conferences raise the international profile of South African research and development. In recent years there has been an increase in international delegates, mainly from Europe and the USA but with some also coming from Asia and Australasia. Today, RAPDASA continues to have close links with the Global Alliance of RP Associations (GARPA).

\section{Comparison to Previous Road-map}

The developments that have been discussed are now compared to the previous road-map (Campbell and de Beer, 2005) to ascertain if any actions were overlooked or if subsequent new lessons can be learnt.

\subsection{Increased Participation of Industry within National RP Networks}

There has been continual industrial participation within RAPDASA management and events. The involvement of RP vendors at the past few conferences has been particularly noticeable through the increased number of booths exhibited. The involvement of SMME's within RP activities has also been encouraged through the Technology and Human Resources for Industry Programme (THRIP) run by the National Research Foundation. THRIP aims to boost South African industry by supporting research and technology development, and by enhancing the quality and quantity of appropriately skilled people (NRF, 2009). THRIP challenges companies to match government funding for innovative research and development, which in turn is co-funded by local and international firms with the RSA's Department of Trade and Industry (NRF, 2009). The ability for 
this programme to successfully encourage companies to use RP was evidenced by Stellenbosch University and the CUT which have both won THRIP excellence awards.

\subsection{Product Development Embracing the Use of Digital Tools}

South Africa's technology transfer strategy has been generally successful with more companies embracing RP/AM technology and buying machines. Indeed, the growth of RP purchases within industry is now well above that seen in academia (de Beer, 2008). Most of these have been 3D printers but some high end systems have also been purchased. At the same time, the growth in the use of digital tools such as CAD and RP software is evidenced by increased system sales, as seen by Materialise for their offerings. Further growth in the use of CAD could be expected if its use within South African schools become mainstream. This is one of the aims spearheaded by the DesigNation initiative launched in 2005 by the National Product Development Centre (NPDC) of the CSIR. However, the NPDC ceased to exist due to internal restructuring of the CSIR, and the initiative continued with only limited success until 2007.

\subsection{Strengthening of International Links}

As the use of RP and research in South Africa is being developed, Centres of Excellence are beginning to emerge. Some of these are internationally recognised and have resulted in South African institutions being invited to join international partnerships. For instance, the CUT has a joint partnership with the EOS eManufacturing program, and Stellenbosch University (SU) has a formal agreement with Fraunhofer to establish JointLab. Other examples of strengthening international links are the successful involvement of Professor Deon de Beer of VUT and Professor Dimitri Dimitrov of Stellenbosch University in collaboration schemes such as the Commonwealth Scholarships Programme (UK), Royal Society Research Networks (UK), German Technical Cooperation Programme or GTZ, NRF-Germany Bilateral Agreement, NRFPoland Bilateral Agreement and a Visiting Professorship at the Polytechnic Institute of Leiria (Portugal).

\subsection{RSA as a Conduit for other African Countries}

Promotion of RP/AM amongst other African countries has come mainly through the activities of RAPDASA. Researchers from Namibia, Botswana, Lesotho and Egypt have attended the RAPDASA conferences and returned to their own countries with ideas for future research and development. For example in 2006, Professor Deon de Beer presented the topic of computeraided manufacturing technology for the dental industry at the annual general meeting of the 
Namibian Dental Association. This opportunity came from his long-running association with RAPDASA and the CSIR.

\section{Salient Lessons and Future Directions}

The road-map presented by Campbell and de Beer (2005) remains a relevant strategy for the RSA. Although good progress has been achieved in all four recommendations, it is expected that greater progress should be further desired and achieved. A major obstacle to the wider use of digital product development technologies and the uptake of RP is that access to CAD systems in schools and higher learning institutions is still limited. This presents students with a steeper learning curve when they enter higher learning or industry, which could possibly detract from desire for a career in product development. Without access to CAD and associated downstream technologies, students are not exposed to the creative possibilities of a modern product development process. Therefore, promising students may be lost to other professions such as law or medicine. To counter this, short courses in CAD/CAM have been offered to manufacturers by the National CAD/CAM Training Centre, and the 'CAD in Schools' program was put in place for students at grades 10 - 12 at 25 pilot schools (du Preez et al., 2006). However, subsequent uptake was slow. The CAD in Schools programme had limited funding, and as such it was activated in certain schools only. It did, however, create an awareness and basis for technology adoption in schools.

Further momentum has been gained through the FabLab initiative in South Africa, which although very successful, was limited to the launch/development of seven centres, again due to limited funding. The FabLab initiative aims to give students free access to numerous digital technologies. However, as these FabLabs are situated in urban centres, they may not be reached easily by rural communities. Further centres, together with some mobile FabLab developments, as well as independent initiatives are on the way, which may keep the momentum going. In parallel, RAPDASA has, through support from Wohlers Associates and Stratasys, started with annual outreach activities to schools in disadvantaged regions. The programme, based on the SME Bright Minds initiative, may take over where CAD in Schools has stopped. It is hoped that these programmes will continue to educate and orientate school learners towards taking up a career in manufacturing, together with a working knowledge of CAD, product development and AM. 
To address the lack of consistent access for school age children, the authors propose a fifth recommendation for the road-map. This is to strongly promote the availability of digital technologies in pre-university education that would provide an early foundation for CAD and RP awareness, so as to build up this expertise in undergraduate and postgraduate students.

\section{Conclusion}

This paper has provided examples that show strong growth in the use of RP/AM technologies in the RSA. As more users, systems, applications and research take place, significant challenges must be met. More importantly, the paper provides an update on developments, such as recent government initiatives, growing ownership trends, new applications and novel industrial utilisation of RP/AM technologies. The paper has also highlighted that the education sector in the RSA has been slow to introduce students to digital product development technologies and the use of CAD systems. The authors have proposed a fifth recommendation on the road-map that aims to promote the availability of digital technologies in the RSA's pre-university education.

In looking at a five year trajectory for AM development in RSA, the authors estimate that growth will continue along the current lines in high end machines, driven by specialized applications such as the manufacturing of medical instrumentation through e.g. direct manufacturing in stainless steel, high temperature metal alloys for the aerospace industry, dentistry applications or other specialized applications that may often emanate from research, e.g. micro manufacturing. There is no doubt that the 3D printing market in RSA will have an exponential growth, with new cheaper machines playing an important role. In terms of predicting the growth, the number of machines in RSA is set to go beyond 200 during 2010, and will most probably reach 400 towards the end of 2014. The overarching percentage of these anticipated sales will however, be in the 3D printing category, but more specifically in terms of the new generation of low cost machines.

Whilst AM technologies are becoming more affordable, many users in the RSA still see it as expensive, cumbersome to run and maintain, and with extremely expensive materials, due to the fact that all systems and materials still need to be imported, and this results in much higher costs than conventional materials. The authors have deliberately not looked too far ahead because this could become mere speculation. However, one matter that is likely to have great impact over the next five years, is the availability of very low cost 3D printers such as the RepRap 
machine sold by Bits from Bytes. This will open up yet another swathe of potential RP owners including schools and inventors, leading to a further increase in machine sales.

Finally, in terms of other countries learning from what is happening in the country, Gibson (2008) stated that "RP in South Africa has now moved to a new level and the country can act as a role model for other developing economies". This statement is a clear indicator that South Africa has successfully built upon its foundations in RP and is a now a successful model of "National Best Practice". 


\section{References}

Agrawal, S., Antunes, J.P., Theron, E., Truscott, M. and de Beer, D.J. (2006), "Physical modeling of catchment area by rapid prototyping using GIS data", Rapid Prototyping Journal, 12(2), pp.78-85.

AMTS (2008), Annual Management Report 2008 <http://www.amts.co.za/0708manreport.pdf> (accessed June 2009).

AMTS (2009), <http://www.amts.co.za/inner_provincial_initiative.htm> (accessed June 2009).

Campbell, R.I. and de Beer, D.J., (2005), "Rapid prototyping in South Africa: past present and future", Rapid Prototyping Journal, Vol. 11 No. 4 pp. 260-265.

Campbell, R.I., de Beer, D.J., Barnard, L.J., Booysen, G.J., Truscott, M., Cain, R., Burton, M.J., Gyi, D.E. and Hague, R.J.M., (2007), Design Evolution through Customer Interaction with Functional Prototypes" Journal of Engineering Design, Vol. 18 No. 6 pp. 617-635.

de Beer, D., Booysen, G., Barnard, L. and Truscott, M. (2005a), "Rapid tooling in support of accelerated new product development”, Assembly Automation, Vol. 25 No. 4 pp.306-308.

de Beer, D.J., Truscott, M., Booysen, G.J., Barnard, L.J. and van der Walt, J.G. (2005b), "Rapid manufacturing of patient-specific shielding masks using RP in parallel with metal spraying", Rapid Prototyping Journal, Vol. 11 No. 5 pp.298-303.

de Beer, D.J., Barnard, L.J. and Booysen, G.J., (2004), "Three-dimensional plotting as a visualization aid for architectural use", Rapid Prototyping Journal, Vol. 10 No. 2 pp.146-151.

de Beer, D.J., (2008) "South Africa 2007 Additive Fabrication (AF) Landscape", RAPDASA Annual RP Growth in South Africa <http://nealdebeer.webwerwe.com/index.php?option=com

content\&view=article\&id=67\&ltemid=83> (accessed February 2010)

Drstvensek, I., Valentan, B., Brajlih, T., Strojnik, T., and Ihan Hren, N. (2009), "Direct Digital Manufacturing as Communication and Implantation Tool in Medicine", US - TURKEY Workshop on Rapid Technologies, September 242009

Dimitrov, D. (2006), "Stellenbosch University, Department of Industrial Engineering proves the value of 3D printing in manufacturing, architecture, and education", 3d Rapid Prototyping Case Studies: Stellenbosch University <http://www.3drapidprototyping.co.za/images/CaseStudyStellenbosch-v03.pdf> (accessed March 2010) 
Dimitrov, D., Schreve, K., Taylor, A. and Vincent, B. (2007a), "Rapid prototyping driven design and realisation of large components", Rapid Prototyping Journal, Vol. 13 No. 2 pp.85-91.

Dimitrov, D., van Wijck, W., de Beer, N. and Dietrich, J. (2007b), "Development, evaluation, and selection of rapid tooling process chains for sand casting of functional prototypes", Proceedings of the Institution of Mechanical Engineers: part B - Journal of Engineering Manufacture, Vol. 221 No. 9 pp.1441-1450.

Dimitrov, D., Schreve, K., de Beer, N., Christiane, P. (2008), "Three Dimensional Printing in the South African Industrial Environment”, South African Journal of Industrial Engineering, Vol. 19 No. 11 pp. $195-213$

du Preez, W.B., de Beer, D.J. (2006), "RAPDASA - A vehicle for product development technology diffusion in South Africa", Proceedings of the All Africa Technology Diffusion Conference, Boksburg, South Africa, June, pp 11.

Fab Lab (2009), <http://fab.cbc.mit.edu> (accessed June 2009).

Gibson, I. (2008), “GARPA Column”, Time Compression Technologies Magazine, Vol. 16 No. 2 p.10.

Haskins, S. (2008), "3-D prototyping cuts time, costs" Engineering News, April 2008 http://www.engineeringnews.co.za/article/3d-prototyping-cuts-time-costs-2008-04-11 (accessed February 2010).

NRF (2009), <http://www.nrf.ac.za/thrip/> (accessed June 2009).

Truscott, M., de Beer, D., Vicatos, G., Hosking, K., Barnard, L., Booysen, G. and Campbell, R.I. (2007) "Using RP to promote collaborative design of customised medical implants", Rapid Prototyping Journal, Vol. 13 No. 2 pp. 107-114.

Tshumisano (2009), <http://www.tshumisano.co.za/home.php> (accessed June 2009).

Wohlers, T. (2006), "Wohlers Report 2006: State of the Industry Report Annual Worldwide Progress Report", Wohlers Associates, Inc., Fort Collins.

Wohlers, T. (2007), "Wohlers Report 2007: State of the Industry Report Annual Worldwide Progress Report", Wohlers Associates, Inc., Fort Collins. 
Wohlers, T. (2008), "Wohlers Report 2008: State of the Industry Report Annual Worldwide Progress Report", Wohlers Associates, Inc., Fort Collins.

Wohlers, T. (2009), "Wohlers Report 2009: State of the Industry Report Annual Worldwide Progress Report”, Wohlers Associates, Inc., Fort Collins. 